\title{
Teaching and Learning the Electric Guitar: A Case Study in a Singaporean Higher Education Teacher-Preparation Institution
}

\section{Larry Hilarian Francis}

National Institute of Education, Singapore

larry.hilarian@nie.edu.sg

\section{Eugene Dairianathan}

National Institute of Education, Singapore

eugene.d@nie.edu.sg

\begin{abstract}
Many electric guitarists have earned their reputation as expert performers and connoisseurs, despite the absence, at least until very recently, of school-based curricula or internationally recognised examination bodies, and usually without any institution to validate their credentials. Despite recent initiatives to support new pedagogical paradigms in teaching and learning, teachers of the electric guitar continue to be confronted with problems of preparing learners for soundscapes beyond a gig setting or one of the recent electric guitar examinations. Instrumental fluency cannot be understood merely as a function of mechanical achievement (that is, musical and instrumental techniques), but as a function of human capacity as "instrumentality": how "human beings have puzzled over [...] something they acquire without knowing how, that they possess but which something possesses them even more, that is not a part of them but without which they would not be what they are" (Sigaut 2002: 421). This paper is based on a case-study with an undergraduate music education trainee teacher at the National Institute of Education, Nanyang Technological University who undertook lessons with a
\end{abstract}


music faculty member in the electric guitar as part of his music ensemble activities. The findings from this interaction explore an electric guitar practitioner's technology in four ways: first as a musical and instrumental technique which has been consolidated in the global practice of electric guitarists; second as a way of devising strategies to study electric guitar within its own unique glocal soundscape; third, as a way of encouraging learners across social and cultural contexts to find their own voice through the instrument; and fourth, through these means, to come to terms with the difference and distance between the practitioner-as-learner, and the learner-as-future-classroom teacher/practitioner.

KEYWORDS: electric guitar, instrumentality, teaching and learning, practitioner-as-learner, music education, teacher preparation

\section{Introduction}

The good thing about the guitar was that they didn't teach it in school. Teaching myself was the first and most important part of my education... I hope they keep it out of the schools. (Jimmy Page, cited in Davis 1985: 16, in Lilliestam 1996: 207)

The electric guitar has come to be recognised as one of the most enduring of musical instruments in popular culture, partly perhaps because of what it symbolises and embodies; as well as the incredible flexibility, subtlety and expressive potential of the instrument. Despite recent initiatives to support endeavour in and through the electric guitar, teaching and learning of this instrument is still confronted with problems of preparing learners within the relatively uncharted space of formal education in schools and in instrumental studios. The possibilities of teaching and learning in and through the electric guitar in formal education therefore pose challenges of instrumental and institutional support; not only in the teaching and learning context, but also in the preparation of teachers.

The assertion by Jimmy Page, lead guitarist from Led Zeppelin, is instructive in a number of ways. The first alludes to the absence of the guitar in mainstream schooling when he was at school in Britain during the 1940s and 1950s. Also implicit in this absence is a tension between the instrument and school as avenues towards excellence in performance. Yet, skill acquisition and the development of curriculum and pedagogy in relation to instrumental techniques are valorised and supported through established conventions and standards of excellence, and emerge substantially as learned, conditioned and disciplined behaviour. Considering the prevalence of elementary through tertiary school-based instrumental programmes for string, wind, brass and percussion instruments in the USA and many other countries even today, why has the electric guitar seemed to have escaped notice in a formal school-based curriculum?

That the electric guitar was not taught in school results from negative associations with rock music. Nearly fifty years ago, Fowler (1970: 38) identified three central arguments by North American school teachers for not including rock music in the school curriculum: 
1. Rock music is aesthetically inferior music, if it is music at all;

2. Rock is damaging to youth, both physically and morally; and

3. School-time should not be expended teaching what is easily acquired in the vernacular.

Three decades later, a further three reasons were identified to account for this resistance:

1. Traditional teacher education has not provided substantial training in rock music;

2. Rock music is viewed as rebellious and anti-educational, characteristics that problematise its appropriation by teachers; and,

3. Effective instructional curriculum for rock music is relatively difficult to acquire in the United States. (Herbert and Campbell 2000:16)

Similar responses were also found in the United Kingdom by Vulliamy (1977a, 1977b) and Green (1988); although by the turn of the century opinions as well as practices had changed considerably in that region (see Green 2002); and in many parts of Scandinavia the electric guitar has been a common instrument in the school for thirty years (Karlsen 2010).

Related to the forces of repulsion are also forces of attraction. Page's assertions suggest how learners of the electric guitar have traditionally been self-taught, learning through oral and aural transmission, a situation which persisted into the twenty-first century and is still going on today (see for example Green 2001). The electric guitar has been more meaningfully managed through guitar magazines, concerts, recordings, jam sessions and more recently online resources such as social media and YouTube, to name but two. Although Music examination syndicates have recently begun to influence behaviours towards the formalisation of assessable components, they are driven very much by approaches which are conceived and implemented outside instrumental or classroom-based modes of teaching and learning.

Until recently most, if not all practitioners have established their own musical credentials, in the relative absence of a formal school-based curriculum and/or internationally recognised examination bodies or institutions to validate them. Implicit in this observation of absence in the school is an absence of such avenues towards aspirations and achievements. Yet, as of course with most if not all musical instruments, electric guitar practitioners' achievements resonate with a point of arrival in Abraham Maslow's observations of enabled individuals in creative moments - in immediacy and in memory - as self-transcendence (Maslow 1971: 165).

Related to the instrument and school, the instrument and instrumentality are also manifest. By instrumentality, we mean the ability of the instrumentalist to redefine individual expressivity through the instrument, and that hinges on the instrumentalist and the environment which nurture such individuality. To take a cue from instrumental programmes, instrumental proficiency is valorised through programmed instruction, or instrumentality as technology. But if technology is understood as material actions by human behaviours, instrumentality acquires an 
expressivity unique to the instrumentalist. It is the individual instrumentalist that raises the awareness of expressivity unique to the instrument; hence instrumentality as technology.

[I]n the sense that they [human actions and human behaviours] all make a material change in something; and that they are intentional and are so on several levels [...] the social goals have taken the form of material needs and these have become the agent's true goals [...T] he activities [...] are not simply material, they are intentionally material (Sigaut, 2002: 424, emphasis in original).

School-based instrumental programmes do valorize expressivity through the instrument, but may amount only to skills of literacy playing music from notated scores. Such skill points to a social ensemble that leans towards compliant rather than consensual readership. Heuser (2011: 293) argues how

[p]ublic school music education in the USA remains wedded to large ensemble performance. Instruction tends to be teacher directed, relies on styles from the Western canon and exhibits little concern for musical interests of students. The idea that a fundamental purpose of education is the creation of a just society is difficult for many music teachers who dream of conducting student musicians in polished performances.

Heuser's account corroborates Allsup and Benedict's (2008: 157) description of how the American wind band is seen to

stem from an inheritance that is overwhelmed by tradition, an episteme that represents its success in terms that are very familiar to the spirit of American competitiveness, efficiency, exceptionalism, and means-ends pragmatism. Persons who come to and from replicas of these historic programs are individuals submerged by the rules of its practice and are thus likely to embody class situations that are bound by its discourses: belief in strong leadership, belief in commitment to a larger collective, belief in meritocracy. Internal critique, consequently, appears inviolable.

This form of skill-acquisition is some distance removed from what I call conciliatory readership (when leader and ensemble members agree to being led for the sake of the ensemble) and a dialogic readership when differences distinguish expressivity in or despite an ensemble.

The electric guitar, amongst other instruments with similar musical and historical lineages, somehow enables and engages all three forms of readership, albeit in different and differing ways. This is because learning to play - in this case - the electric guitar acknowledges the primacy of oral and aural experiences not found in notated scores, and how those forms of experiential transmission form individualized proficiency through imitation, emulation, experimentation and exploration, as well as how much of a guitarscape that emerges through the person playing the electric guitar reveals cultural influences not necessarily matched with those these learners have relied on for influence and inspiration. Much of this learning is time-consuming, not easily amenable to a structured programme, and places a premium on lived realities. 
Musical practices involving the electric guitar are then uncomfortably poised between systemic lived practices and systematic discourses through institutional support and legitimisation. In the words of John Blacking (1995: 23-24), "while musical systems are related to social institutions, the relationship is dialectical, dynamic and highly problematic". Following Blacking's observation, the dynamics of the electric guitar within its own systemic lived practices (Fender versus Gibson Les Paul as one of many examples) encounter other problematic relationships. If systemic practice has identified with its principal protagonists by establishing its own standards of excellence, should the electric guitar be considered as an instrument for generalist participation? Could systemic practices of the electric guitar be transposed to establishing teaching and learning modes for a school-going population? On the other hand, what would be the justification when a greater majority of established electric-guitar practitioners have not needed enablement through their school-based learning? Given that principal protagonists of the electric guitar have been granted the forms of freedom usually enshrined in jazz, and its repertoire contemporaneous with lived reality, should we take cognizance of Page's suggestion that the electric guitar should be kept out of school? Another reading might be that the electric guitar in a school-based context potentially devalues the electric guitar which in its out-of-school context has enabled individuals towards creative moments (and creative behaviours by association) that Maslow (1971: 165) identifies as self-actualisation and even selftranscendance. It must, however, also be noted that for young people today the electric guitar may seem as old as a violin, being associated more strongly with the music of their parents' generation that the new music of their own.

\title{
Electric guitar, popular music and schooling
}

The significance of the electric guitar in popular music and school-based infrastructures resonates with Paul Willis' contemplation, albeit the context in England but arguably transposable worldwide, on the tensions between policy and practice in contemporary discussions which includes schools and students:

\begin{abstract}
Young people are unconscious foot soldiers [...] involuntary and disoriented conscripts in battles never explained [...] students are rendered by statemandated education into compulsory living materials of future imaginings and moldings [...] without the rudiments of a sociological or ethnographic imagination [...] Power brokers and policy planners are transfixed by $[\ldots]$ their "top-down" practices and initiatives; however, they fail to ponder the frequently ironic and unintended consequences of these practices and the creative cultural ways [...] "bottom-up" responses are often informed by quite different social perceptions, practices and assumptions (Willis 2006: 507 in Dairianathan and Hilarian 2012: 91-92).
\end{abstract}

The mismatching of outcomes between top-down and bottom-up trajectories, Willis argues, is most keenly felt among those at the formative stages of both school and workplace: "Schools are one of the principal sites for the dialectical playing out of these apparent disjunctions and contradictions, which while misunderstood, underlie some of the most urgent education debates - from 
traditionalism versus progressivism to the canon versus multiculturalism" (Willis 2006: 507-508).

In expressing the need for a social understanding of education to consider topdown practices and bottom-up responses and the ways in which they interact "on the ground" to produce the complex eddies, waves and flows of modernisation, Willis identifies three waves of cultural modernisation "from below":

1. Cultural responses to Universal schooling;

2. Responses to the Post-industrial Society; and,

3. Commodity and Electronic Culture (ibid.: 508-515, emphasis in original).

The point of Willis' observations is that the school is the direct instrument of the first wave; it suffers disorientation from the second wave, and is an important site for the playing out of the third wave of modernisation (ibid.: 519). This third perspective, on the multiple uses of popular culture and media by youth, is a phenomenon Willis calls common culture:

\begin{abstract}
All school students are drawn in to the field of force of popular culture provision...commodity-related expressive consumption - or common culture - does not take place in a vacuum or simply repeat the exploited meanings of commodity production [...] In the school, this points to the importance of understanding popular cultural consumption with respect to previously existing themes of school conformism, resistance, disaffection, variations and points between them. (ibid.: 517)
\end{abstract}

Given popular culture's pervasiveness and propensity for use value, Willis (ibid.: 518) argues:

\begin{abstract}
Popular culture should be understood in relation to the strong urge of young people to make and maintain a viable informal cultural identity acknowledged by others in shared social space [...] The school is a crucial site for these grounds where an over-mapping of distinctions takes place, with common culture positions and identities mapping onto distinctions within the school and these distinctions themselves mapping onto wider social distinctions....perhaps it is the singular nature of the modernist school where people of the same age are forced into a common arena that compels individuals and groups to find a place within a single complex matrix.
\end{abstract}

These musings have prior resonances with explorations by Green and Lindgren and Ericsson in a discussion of the choice of instruments used by learners in the school. Green (2005: 28) and Lindgren and Ericsson (2010: 41) point out that the electric guitar is part of a rock band configuration as part of a creative and/or recreative music-making process. Implicit in their context however, is the unquestioned notion of the presence of these instruments in a classroom recreative environment. Also not considered is the possible presence of a facilitator and/or mentor who may be proficient in the electric guitar who may offer support for those wishing to learn the electric guitar in such settings but have not the prior knowledge. 
These issues are crucial to our paper because of the need to contextualize both aspects and situate them in an educational landscape in Singapore in as much as they pertain to popular music education - as policy and practice - in schools for students aged seven through fourteen. The forthcoming General Music Programme 2015 syllabus (GMP hereafter) for Singapore schools (MOE 2014) aims to develop awareness and appreciation of music in local and global cultures, develop ability for creative expression and communication through music, and provide the basis to develop an informed and life-long involvement in music (2014: 2). The Ministry also identifies five learning objectives for engaging in music creating, performing and responding (individually and in groups).

1. Perform Music in both instrumental and vocal settings;

2. Create Music in both instrumental and vocal settings;

3. Listen and Respond to Music;

4. Appreciate Music in local and global cultures; and,

5. Understand musical elements and concepts (MOE 2014: 4-7)

While many of the syllabus aims and objectives are based on the previous (MOE 2008) articulation, the single telling change is an emphasis on individual students being enabled through what it calls classroom and melodic instruments (recorder, keyboard, guitar, ukulele and instruments learnt through Co-Curricula Activities such as Symphonic Band, Choir, etc.).

This paper also recognises the context and issues surrounding the school as a possible space for the electric guitar as a melodic instrument, as instrumentality for individuals to be enabled, and institutional support for such enablement. The extent to which the electric guitar can co-exist in a school environment - like other instruments and instrumental ensembles - rests to some extent on which teacher competencies and competence in electric guitar teaching and learning are available in schools; which is the extent to which the teacher of the electric guitar in a school has been enabled at teacher-preparation contexts and institutions (and this is separate from itinerant electric-guitar teachers or a vendor system which a school may purchase, including syllabuses, technical and specialist teaching resources).

Therefore, this paper explores these challenges, focussing attention on the preparatory strategies in the acquisition of instrumentality of skill-sets in the electric guitar, before facilitation and support in formal teaching and learning. The paper chronicles teaching and learning strategies in and for the electric guitar by focussing on exploratory interactions between a Music faculty member (an electric guitarist who developed his skills purely informally) and a Music Education undergraduate (also an electric guitarist with an informal background) over the duration of his Music Education programme (July 2009 - June 2012). Given the nature and duration of these interactions, both Dairianathan (hereafter LF) and student-teacher (hereafter GT) reflect on their narratives in these attempts at negotiating teaching and learning involving the electric guitar at a teacher preparation institute (with the Singapore National Institute of Education as the example). The paper reflects on both these narratives and suggests one approach negotiated between LF and GT towards the teaching and learning of the electric guitar as an avenue for educational access and opportunity in a school 
infrastructure to "celebrate the diversity and variety of all that is before them" (Lum and Dairianathan 2013: 347).

\section{Context}

The National Institute of Education (NIE), Nanyang Technological University in Singapore is the sole provider of teacher preparation for Singapore schools (primary, secondary and pre-university levels) through its initial, in-service and graduate programmes. The Ministry of Education as sole provider of student teachers has primary decision-making authority in determining eligibility for teacher preparation programmes at NIE. Upon graduation, all student teachers are deployed to teach in Singapore schools.

All music specialists in the undergraduate Music Education programme are offered principal instrumental studies (paid for by the institution) for which they are required to present end of year and graduation recitals. In addition to their main instrumental study, they are required to participate in a world musics ensemble and another from a selection of performance-based ensembles (Percussion, Gamelan and Shakuhachi ensembles, Classical Guitar, Choir and Symphonic Band ensembles) or independently-formed ensembles ranging from Recorder, Piano, Ukulele, Boomwhackers, "Pop band" and even ICT-based ensembles such as the I-band. These musical ensembles carry with them a mandatory pass option attached to their core and prescribed courses. If they fail in the assessments, they fail their entire core/prescribed courses.

Almost all of the Music students have opted for the "Popular Music" ensemble; bringing their own impressions of popular music repertoire as well as popular music they were able to take ownership through their performance. An unrestricted elective Studies in Pop and Jazz (AAI 485) has been offered by Dairianathan (as an established local electric guitar practitioner) since 1993, which has been the most consistently well-subscribed course from across the University.

At the beginning of the undergraduate Music Education programme in 1993, instruments of study comprised largely piano, violin and voice, more rarely clarinet, flute and percussion. Negotiations between officers at the Ministry and Music faculty about the need for accessibility, relevance as well as inclusivity and diversity in the choice of Music specialists has, since the millennium, seen students offering instruments from the Chinese orchestral ensemble - dizi, guzheng, sheng, chongruan, yangqin and erhu - as well as Wind ensemble instruments, such as the trombone, tuba and euphonium. In terms of popular music, there were students offering electronic organ and acoustic guitar; the latter electing to offer classical guitar as his principal study.

In 2009, one among the Music Education undergraduates, GT, auditioned for a place in the Music Education programme with Metallica's "Nothing Else Matters"; albeit on an acoustic guitar. At the stage of his audition, we had not been apprised of his decision not to use an electric guitar. The music department was in possession of instruments and supporting resources to allow GT to offer the electric guitar as his main instrumental study. GT's recollection of the audition was that: 
Since I learnt it informally, maybe I somehow felt that there wasn't such a thing as an "electric guitar main study" in such an institution. To me, it has been always kept out of formalised contexts, so i naturally assumed that there it wasn't even a possibility to study it formally at NIE. At first I was under the impression that there weren't resources available for me to offer the electric guitar as my main study [this was before he met LF who was not present at the auditions]. I was given an instrumental tutor's contact and after initial interactions, and realising that he was more of a Classical Guitarist, decided to embark on learning the Classical Guitar from scratch. I think my perspective and identity as a musician wasn't one that was insistent that I MUST offer the electric guitar as a main study. Besides, I was cool with the Classical Guitar because i felt it was going to be a challenge and I knew that somehow it was going to supplement me as a guitarist... I was just glad to be receiving musical training and these differences didn't matter as much to me. (E-mail correspondence with authors, June 2014, emphasis in original)

This was again corroborated in his reflections in the later years of the programme:

[M]y prior experiences playing in a rock band in Secondary school and JC were [experiences] seldom seen or heard in music lessons or at school functions... something outside the system... not fortunate enough to have learning experiences because it is not treated as a legitimate form of music taught in the classroom, and lack of training, understanding and/or experiences in it on the teacher's part. (Dairianathan and Hilarian 2012: 9899, emphasis in original).

It should not surprise us, given his lived experiences of playing in a rock band as a teenager, that his reflections resonated with Jimmy Page's quoted earlier. Moreover, this only served to speculate on the equal problem of advocating the playing of the electric guitar in school as a future serving teacher and supporting students in the teaching and learning of it. Nevertheless, GT was sufficiently motivated to begin studies in Classical Guitar "from scratch". Because of the ensemble infrastructure in the Music department, GT was enabled to continue to improve his electric guitar playing in Pop band ensembles and sought mentorship from LF during his four year programme at NIE.

This paper now considers the approaches undertaken, in separate facilitations, by LF to support GT's electric guitar proficiency and considers the technologies (see Sigaut 2002) of being enabled in and through the electric guitar in four ways: as a musical and instrumental technique which is consolidated in the global practice of electric guitarists; as a way of devising strategies to study electric guitar within its own unique soundscape; as a way of encouraging learners to find their own voice through the instrument; and, through these means, to come to terms with the difference and distance between the practitioner-as-learner, and the learner-as-future-teacher/practitioner.

\section{Diagnostics}

$\mathrm{LF}^{\prime}$ 's immediate concerns were how to gauge progressive learning between both teacher and learner and by what forms of appropriate assessment tasks to 
determine the level of achievable learning goals and progress by evaluating our own teaching strengths and weaknesses. LF considered teaching approaches and motivation, and formative and intermediate assessments, while gauging how evaluation could be considered verifiable and reliable. Alongside the aims, there are also two main learning objectives. Engaging in a variety of teaching approaches would help GT, but what about transferability towards GT assessing and evaluating his future learners' progress?

\title{
Teaching approaches
}

In his years as an informally trained (and professional gig) musician, later instrumental and classroom facilitator, motivation for LF was and is a function of a learner desiring (contra wanting) to be able to play fluently and confidently. The first of LF's concerns was choice of popular music repertoire. LF had been nourished through a repertoire of Hawaiian guitar through early psychedelic rock repertoire. GT preferred music of the blues, rock and metal from the 1970s and 1980s; a generation after. Could LF command respect in enthusing GT?

A second consideration in nurturing GT was discipline. Given the motivation, did GT possess the discipline and perseverance to pursue his ideals? Because of his prior background, GT could imitate solo passages from popular music repertoire familiar to him with ease. He seemed to have a much better understanding of learning more complex rhythm and strumming techniques without much difficulty. GT, at first, possessed much of the intrinsic and extrinsic motivation which was an invaluable beginning. But was it enough? For GT:

\begin{abstract}
Motivation was one of the key factors to my engagement which stemmed from two sources: 1) My own passion for the electric guitar and its related musical genres, and, 2) my musical background as an informally trained electric guitarist. because of LF's own musical background, experience and familiarity of informal learning pathways, he would be an ideal mentor to me; he would understand how I approached learning new musical concepts; quite different as compared to a classically trained musician. Motivation was further maintained within LF's electric guitar classes by allowing differentiated learning by tailoring individual goals and expectations rather than one that is homogenous. (E-mail correspondence with authors, June 2014)
\end{abstract}

\section{Chord grammar and musical knowledge}

What did LF know of GT's musico-technical predispositions? Was GT as capable in LF's view of being able and enabled towards "live performances" among practitioners? Exactly what were GT's dispositions, and by consequence, predispositions and in-dispositions? Furthermore, GT was still trying to maintain two very different guitar traditions - classical and electric guitar - he encountered some initial problems with the plectrum techniques, especially with the up and down pick movement. Might these challenges be overwhelming for GT? 
With these challenges in mind, the assessment tasks LF set out concentrated on understanding chord grammar and musical knowledge, scales, modes and arpeggios, strumming and rhythm articulation, and improvisation. Given LF's diagnostic evaluation of GT, these were the tasks which formed and informed eventually more essential musical elements for GT to learn to perform in lived reality; in and out of school. With these four musical elements, LF was concerned with not only how learning takes place but also how playing the electric guitar could become part of a wider "social experience" through the act of performing. The teaching of chords in isolation was, in LF's experience, generally unproductive. He found that students acquired better understand of playing chords (chord sequence) when studied within a larger framework, lived reality being the largest. For example, jamming with a twelve-bar blues sequence in various keys aided the spatial-motor movement of the hand (right hand) position for the playing of various chord shapes on the fingerboard. Greater understanding of technical demands could be better overcome with adapting appropriate application of instrumental techniques and technical application on the instrument. Role swapping (between lead [melody] and rhythm [chord] playing) enthused, engaged, and extended learners by extending them in ways not possible through out-of-context technical exercises. LF discovered that GT was extremely comfortable and confident in responding and adapting to swapping roles between lead and rhythm playing; his prior experience of playing the electric guitar being a crucial factor. His commendable musicianship skills notwithstanding, his prior knowledge (or lack) of rudimentary musical theory and chord vocabulary to aid performance (including score reading, theoretical understanding of chord formation, grammar and syntax), made it difficult for GT to transpose his musical ideas easily. LF's solution to GT's situated context was to engender the use of the twelve-bar blues chord sequence, as an accessible musical structure, to understand-by-engaging in form and structure for improvising and creating within and beyond the structure. Clarity was most suitably negotiated by playing through this structure for access to other genres. Learning was also complemented with musico-theoretical and historical knowledge, some of which GT was reading for in his programme of study while other knowings involved his own research.

This was an important step in LF's strategies according to GT:

Firstly, the nature of these jam sessions - allowing the space to make mistakes, was very important in helping me develop a confidence in "taking risks" and trying out new material. I was able to hear for myself why certain melodic phrasings or a certain choice of notes couldn't fit so well within a certain chord progression where in theory it should have. Having this opportunity to jam to different chord progressions used in various genres of music encouraged us to experiment with and learn why we can't apply the scales in the same way all the time. For example, the blues scale would be used differently in a slow blues progression as compared to a faster blues shuffle. We were able to develop a type of musicality that enabled us to improvise something that would "sound better" or be more appropriate, given the different contexts. Having given the space to encounter these mistakes, it allows us to think more creatively towards the art of improvising, and to help us come up with original material to be used in improvisation, instead on only relying on "stock phrases". Having the demonstrations and the 
encouragement that comes from jamming together with your peers and mentor helped greatly in the exams as we have improvisation sessions weekly, so I felt that assessment wasn't as daunting even though it required me to improvise over a chord progression spontaneously.

(E-mail correspondence with authors, June 2014)

\section{The Electric guitar as instrument/ality}

Because of GT's prior experiences, LF did not take for granted GT's need to understand the instrument beyond its utilitarian value. LF pursued with GT an understanding of the electric guitar: beginning with its construction; its reliance on auxiliary systems of propagation (amplification); fingerboard structure with its chord shapes and positions; translations through fretboard diagrams; techniques of finger and plectrum; not forgetting individual expressivity through some of these "technologies". LF began and continued the interplay between instrument and instrumentality by focusing on developing improvisation and understanding chord progression, that is twelve bar blues structures in active performance. If at first this was difficult, LF began by a slow demonstration of the playing of chords through slower rhythmic articulation, aiding the learning of chord shapes and also the art and technique of strumming. It eventually dawned on GT that the learning of chord patterns could be expressed in cipher and tablature notation indicated with numbers to represent frets for the individual notes. The strumming of chords could be best understood using cipher notation on a chart with alphabet (A to $G$ ) to identify each chord. Given his earlier immersion with the electric guitar, GT was very comfortable with different styles of syncopated rhythm and strumming techniques.

\section{Techniques: Scales and modes}

Scales and modes remained for LF challenges among initial learners to playing and internalising because it is not possible to envision longer-term benefits to such tasks, let alone how these tasks become pivotal to improvisation. GT adapted to the study of these musical elements very easily but demonstrated impatience in the disciplined learning and lacked the consistency and accuracy of playing them. GT realised later how much more fluidly he could perform and improvise using these patterns. LF experimented further with GT on the use of a descending chord sequence [Am / G / F / E] (also called an Andalucian cadence, see WNYC 2014) as the basis for improvisation using an " $A$ " dorian mode which LF felt gave a better sense of re-creating melodic phrases for improvisation.

For GT, technique, as means and end, was a revisiting of familiarity with capabilities:

When i first started learning the guitar, there was a very clear end in mind - to be able to play the music that $\mathrm{i}$ wanted to. To get to that stage, $\mathrm{i}$ relied on 
listening to records and trying to figure out the pitches and chords to replicate them on the guitar. Along the way, I decided I had to learn tablatures, and some simple exercises on strumming, picking and fingering to be able to play music of increasing difficulties, as listening alone wouldn't enable me to play more complex passages. Most of the time, the techniques that I used in guitar playing were improvised by trial and error - there wasn't a consciousness of whether these techniques were correct or wrong - as long as it enabled me to play the music proficiently, then it's right to me. This aspect of trial and error was important in LF's approach, as compared to a classical approach. LF placed more emphasis on the music we produced - paying more attention to tone, rhythm, etc. He would be conscious of our technique and provide suggestions and alternatives rather than dictate only one way to do it. When learning scales, he would almost always superimpose scale practice with real examples of music - demonstrating how the scales make sense in real examples of music whilst emphasizing the importance of practising these scales to achieve the fluidity for us to be able to use them within chord progressions; the performative end was always present. LF's mentoring was far more effective in developing my musicality as compared to my beginnings, where it was self-taught. Having an experienced practitioner to demonstrate various musical possibilities allowed me to be constantly challenged to improve. When it was self-taught, the learning usually ended where i was able to achieve imitating or "covering" the songs that i set out to learn. With that, my development and creativity was by and large determined by the songs i chose to learn. This meant that often, I'd reach a plateau in my development, always within my musical comfort zone. LF challenged me to learn how to play music in genres beyond this comfort zone. Even in genres that were familiar to me, his demonstrations showed me that there were still much more musical possibilities to think about and explore when approaching them. For example, in learning "Nothing Else Matters", or "Stairway to Heaven", it led me to overcome the challenge of learning for to fingerpick in a way very similar to the Classical Guitar method. Although both songs are well within the Rock and Metal genre, these songs demanded more than just the usual strumming of the power chords - in a way, for those two pieces, $\mathrm{i}$ had to learn and utilise and switch between both Classical fingerpicking styles and plectrum picking for various parts of the solos. Most of "Stairway to Heaven" required me to learn how to fingerpick, but for the electric guitar solo, i had to switch back to the electric guitar style and aggressiveness. Additionally, when learning to play "Paranoid Android" by Radiohead, I was introduced to some Jazz picking techniques and chord positions - which was an entirely different challenge altogether. Most Black Metal pieces presented a rhythmic/ tempo challenge of playing in a very high tempo - learning how to do "tremolo picking" and switching chords up and down the fret board rapidly. When I was going through a Ska/Reggae phase, I had to struggle with the off-beat accents - highly difficult to accomplish alone. For this, I couldnt only rely on playing along with the records. To fully understand the ska "feel", I would have had to do it with a friend who either played the bass or melodic parts or even know the feel and style. This was the most valuable aspect of the mentoring I received from LF. (E-mail correspondence with authors, June 2014) 


\section{Improvisation}

For LF, "the electric guitar is a social instrument which is constantly engaged in an ensemble or band setting with abundant opportunities to improvise". LF worked with GT beginning first with the twelve bar blues chord sequence, applying modal, scalar and arpeggiated patterns to experimenting through improvisation. GT, in his estimation, was demonstrably more successful in improvising because he had in the past imitated and memorized memorable guitar "riffs" and melodic phrases (licks) towards developing his own style. He was over time enabled to transpose and deploy melodic phrases and licks to chord sequences or tunes in ways he deemed appropriate. Initially, LF experimented with GT on switching roles between rhythmic profiency (chord/strumming) and melodic proficiency (lead melody/lead tune). Practising these patterns not only developed fluency, confidence and creativity but was also closely associated with the harmonies using the twelve-bar blues structure. With confident articulation, LF made GT play with recorded rhythmic accompaniment and later, with other experienced musicians (who were known to LF and understood his intentions in developing GT's abilities). This experience, received through playing with other accomplished improvisers, affirmed and reinforced both skills, learning to improvise and improvising to learn. In the beginning, GT demonstrated limited knowledge of how to improvise. This was probably because he had learnt to imitate more than innovate. LF showed him a few variations and he had to take some ideas from LF's demonstrations with him and he could change it to suit his own style. His rhythmic articulation was weak, so LF made GT shadow his playing in the background to gain confidence in rhythmic dexterity.

\section{Repertoire}

For LF, a music teacher has to be inspiring, must be equally fluent on his/her instrument, must possess effective background knowledge of the student's interest in the various types of popular music genres such as, funk, rock, top 40's hits, blues, reggae etc., so that the learner may be motivated to be passionate about learning. Passion can be acquired, but motivation has to be cultivated within realistic goals. The image of "guitar heroes" and imitating them has become motivation for aspiring guitar players. Youth and youth culture seem intrinsically tied to popular music and motivations of prominence to achieve this goal. But such goals needed to be sustained by and with discipline, interest and careful nurturing. Equally important was also the professional role of the guitar teacher who needs to demonstrate, by example, initiative, proficiency and capability to respond adequately to the needs of the learner. GT was also learning the classical guitar which would have enhanced his playing because of a decided focus on instrumental technique, albeit differing genres. LF also introduced GT to flamenco, bossa nova and jazz, which, in these performing modes, made strumming demands on rhythmic proficiency not usually encountered in blues, rock and rhythm ' $\mathrm{n}$ ' blues. Introducing GT to the compás in flamenco, syncopation in jazz rhythms and Afro-Cuban rhythms such as the bembe, son, cha cha and mumbo were challenges that were adopted into his lessons from time 
to time. In the realm of jazz, LF introduced five basic comping rhythms to enable Gideon to integrate skills from his classical guitar playing towards a more holistic and assured foundation for rhythm articulation across a number of genres.

For GT:

The mentoring I received from LF placed focus on performing and listening [...] less emphasis on musical theory and notation [...] making the performance and the improvisation of music the prime focus was very much in line with my own beginnings. There was also an introduction to learning how to perform and improvise in Funk, Jazz, Ska and Reggae exemplars besides the Latin American genres, not forgetting the stock fare for the electric guitar. (E-mail correspondence with authors, June 2014)

\section{Reflections}

Both conventional and non-conventional pedagogical approaches were used to enthuse and elicit learning outcomes, while gauging and evaluating LF's and GT's own teaching and learning strategies respectively. Even as LF had chronicled and documented his solutions towards nurturing GT holistically (not just making his electric guitar pursuits narrowly focused), these "solutions" involved examining and exploring reflexive and reflective pedagogical strategies in ways LF had not attempted before. LF began from self-observation processes (listening) and through listening, the act of learning to perform from a non-conventional pedagogical approach, allowing LF to rely on his life-long experiences of learning to play the electric guitar.

\section{A sense of history}

Music was inextricably and essentially tied to LF's upbringing. His grand-parents were ardent music lovers and he grew-up with the sounds of music surrounding him. However, his parents were ambivalent about music. Therefore, the most important musical influences came from his many uncles who were always engaging in music-making. As a child he was totally exposed to live music, musical instruments and songs played from vinyl recordings. Music-making in his extended family was an essential part of his social-cultural makeup where relatives would come together for "song, music and wine" and merry-making. He was introduced to a wide variety of instruments. His uncles played the Hawaiianguitar, ukulele, banjo, harmonica, home-made tea-chest bass, accordion, numerous kinds of percussion instruments and the one that captured his attention, which was the acoustic guitar. LF was smitten by the guitar and his favourite uncle Michael initially taught him to play chords on the guitar. LF was, by twelve, already playing the guitar confidently by ear as he was introduced to easylistening popular music tunes of the 1950s and 1960s, Country and Western, oldtime jazz favourites (Charlie Christian and Django Reinhart) and also numerous local folk songs. The first guitar his father bought for him was a Hoffner cut-away jazz guitar. When he was fifteen his mother bought him his first Yamaha electric 
guitar and a Tesco guitar amplifier. This was the start of LF's musical journey, learning to perform on the electric guitar. Into his later years, LF was playing at nightclubs and restaurants, most notably with his band D'systems performing at the Tropicana night club (see Chua 2011), interspersed with instrumental teaching at an international school. This was followed by the pursuit of his undergraduate and graduate studies in the UK in Music and Ethnomusicology respectively, the latter degree under the personal tutelage of the late John Blacking. In 1993, LF returned to Singapore as Music faculty at the Music Department of NIE, NTU; an appointment he currently holds.

Eventually, LF's electric guitar practice became an eclectic mix of styles, stemming from his own experiences with classical guitar, flamenco, gambus (pear-shaped lute), bluegrass, jazz and blues. Approaches in his electric guitar pedagogies are then very much a function of his personal relationship with musical diversity. That his pedagogies are also founded on diversity and inclusivity may be perceived to be dilutions of expected performance modes for the electric guitar (especially in rock and metal practices). On balance, LF seems more concerned with the electric guitar as an instrument of possibilities.

In educational terms, however, ways of enablement LF and GT have encountered in their personal and later institutional learning journeys are not dissimilar to Lucy Green's (2004) observations of the ways in which musicians learn through popular musics: enculturation, listening and copying, playing with peers, acquiring technique, informal acquisition of knowledge of technicalities, understanding practicing, coming to terms with "feel", encountering friendship and cooperation, articulation of enjoyment, expressions, implicit or otherwise, of self-esteem, and, appreciation and respect for "other music" (2004: 228-236).

A crucial qualifier however, is not the matching of the ways that Green identified but the pathways and dynamics by which these learning points were navigated and negotiated. Another qualifier was that none of the characteristics were poised sequentially or graduated in any coherent way. More than one characteristic was encountered at any given point in the learning journey; sometimes certain characteristics were more dominant in learning journeys than others, while overlaps among the characteristics took place to reinforce the learning. Although LF began by attempting to legitimise GT's electric guitar practice, he also altered significantly the pathways to learning by extending $\mathrm{GT}^{\prime} \mathrm{s}$ repertoire to include rhythm and blues, jazz and flamenco, to name a few, in addition to learning classical guitar. Rather than investing in a singular performance style for the electric guitar, LF expanded for GT the horizon of performance modes for and beyond what would have been archetypal repertoire for the electric guitar. LF inculcated the discipline of memorising then internalising modes, scales and arpeggios to enable GT - through licks and riffs towards creative and improvisational behaviour.

Both narratives by LF and GT indicate not only a more considered reflection but also a diverse and inclusive repertoire as the basis for being enabled in and through the electric guitar. Diversity and inclusivity have helped encourage pedagogical strategies heretofore not considered. What has not changed in the approach, however, is to continue the enablement through active music-making, playing by ear, playing different repertoire, active participation in jam-sessions and popular music ensembles. Electric guitar players have also developed their 
own musical vocabularies that are shaped by their own expressions, terms, forms, structures and concepts. More than playing by ear (Lilliestam 1996: 197) with its own advantages and drawbacks, this encounter between LF and GT reveals the importance of using strategies of oral and aural learning alongside notational support, envisaged as a continuum of enabling and establishing a higher level of musical competence on the electric guitar.

\section{Conclusion}

Returning to Jimmy Page's assertions, LF and GT seem to have discovered the significance of the electric guitar as instrument and instrumentality towards Maslow's (1971) later considerations of creative moments as self-actualisation and self-transcendance (Koltko-Rivera 2006: 303). One possiblity would have been to have tutored GT towards archetypal electric guitar repertoire. However, LF's approaches favoured the teaching and learning of the electric guitar beyond (at times against) the instrument towards more altruistic and humanist values, towards access and opportunity to the diversity that every learner is entitled to. Herein lies the key to LF's approaches; instrumentality as technology (Sigaut 2002) rather than the instrument as means or end for what was typically heard on an electric guitar. Moreover, as Lindgren and Ericsson (2010: 42) point out, Green's (2005) study has tended to reveal "knowledge formation outside the field of music". We can take this one step further to suggest that the knowledge formation, when internalized, forms and informs the individual (individual as socio-cultural) self, transcending the mechanics of the instrument and instrumental skill-sets as well as the conventions in which the individual derived these knowings.

Instrumentality as technology continues to resonate with GT even beyond his undergraduate learning journey. In his words:

This [diversity] made the learning process fun and organic, a means to an end rather than an end itself. These approaches allowed me to learn effectively and be actively engaged in electric guitar performance and practice, making a lasting impression on my role - as a serving teacher - teaching secondary school students how to play the guitar and perform popular music. (E-mail correspondence with authors, June 2014)

His views, as recipient of electric guitar facilitation at the Music department of $\mathrm{NIE}$, encapsulate a learning journey through the electric guitar:

[I]n allowing for culturally relevant yet musically engaging experience to suit the ever evolving needs and musical identities of our students, the onus would definitely fall on the teachers to meet these demands by empathising, understanding and accommodating it to add value to these out-of-school experiences, legitimising those experiences to allow students to fulfil their musical potential and enjoyment in schools. (Tan 2013)

Tan's observations make for a persuasive call to include the electric guitar "in" rather than "out of" schools. 


\section{References}

Allsup, R. E. and Benedict, C. 2008. The Problems of Band: An Inquiry into the Future of Instrumental Music Education. Philosophy of Music Education Review 16 (2): 156-173.

Blacking, J. 1995. Music, Culture and Experience: Selected Papers of John Blacking. R. Byron Ed. Chicago: University of Chicago Press.

Chua, A. 2011. Tropicana. Singapore Infopedia. http://eresources.nlb.gov.sg/infopedia/articles/SIP_1841_2011-09-25.html. Accessed: 30 March 2014.

Dairianathan, E. and Hilarian, L. 2012. Popular Music and the Classroom. Student Teacher Reflections in Singapore. Proceedings of the 11th Cultural Diversity in Music Education (CDIME) Conference, 4-6 January 2012, Nanyang Academy of Fine Arts (NAFA) and National Institute of Education (NIE), Singapore.

Davis, S. 1985. Hammer of the Gods: The Led Zeppelin Saga. London: William Morrow \& Co.

Fowler C.B. 1970. The Case Against Rock: A Reply. Music Educators Journal 57 (1): 38-42.

Green, L. -

1988. Music on Deaf Ears: Musical Meaning, Ideology, Education. Manchester: Manchester University Press.

2001. How Popular Musicians Learn: A Way Ahead for Music Education. Aldershot: Ashgate.

2002. From the Western Classics to the World: Secondary Music Teachers' Changing Attitudes in England, 1982 and 1998. British Journal of Music Education 19 (1): 5-30.

2004. What Can Music Educators Learn from Popular Musicians? In C.X. Rodriquez Ed. Bridging the Gap: Popular Music and Education. Reston, VA: MENC, The National Association for Music Education: 224-241.

2005. The Music Curriculum as Lived Experience: Children's "Natural" MusicLearning Processes. Music Educators Journal 91 (4): 27-32.

Herbert, D.G. and Campbell, P.S. 2000. Rock Music in American Schools: Positions and Practices Since the 1960s. International Journal of Music Education 36: 14-22.

Heuser, F. 2011. Ensemble-Based Instrumental Music Instruction: Dead-End Tradition or Opportunity for Socially Enlightened Teaching. Music Education Research 13 (3): 293-305.

Karlsen, S. 2010. Boomtown Music Education/Authenticity: Informal Music Learning in Swedish Post-Compulsory Music Education. British Journal of Music Education 27 (1): 35-46.

Koltko-Rivera, M. E. 2006. Rediscovering the Later Version of Maslow's Hierarchy of Needs: Self-Transcendence and Opportunities for Theory, Research, and Unification. Review of General Psychology 10 (4): 302-317.

Lilliestam, L. 1996. On Playing by Ear. Popular Music 15: 195-216.

Lindgren, M. and Ericsson, C. 2010. The Rock Band Context as Discursive Governance in Music Education in Swedish Schools. Action, Criticism, and Theory for Music Education 9 (3): 35-54.

http://act.maydaygroup.org/articles/Lindgren9_3.pdf. Accessed: 1 Dec 2014. 
Lum, C. H., and Dairianathan, E. 2013. Reflexive and Reflective Perspectives of Musical Childhoods in Singapore. In T. Wiggins and P. Shehan Campbell Eds. Oxford Handbook of Children's Musical Cultures. New York: Oxford University Press: 332-349.

Maslow, A. 1971. The Farther Reaches of Human Nature. New York: Viking Press.

MOE (Ministry of Education) -

2008. General Music Programme, Curriculum Planning and Development Division, Singapore.

2014. 2015 Syllabus for the General Music Programme, Student Development Curriculum Division, Singapore.

Sigaut, F. 2002. Technology. In Tim Ingold Ed. Companion Encyclopedia of Anthropology. New York: Routledge: 420-459.

Tan, G. 2013. Striking The Right Chords: A Reflection On Informal Guitar Pedagogy In The Classroom. Proceedings of the 9th Asia Pacific Symposium on Music Education Research ISME Asia-Pacific Regional Conference (APSMER), Republic Polytechnic, Arts Education and the Community, 17-19 July 2013, Singapore.

Vulliamy, G. -

1977a. Music and the Mass Culture Debate. In J. Shepherd, P. Virden, T. Wishart and Vulliamy, G. Eds. Whose Music: A Sociology of Musical Language. London: Latimer New Dimensions.

1977b. Music as a Case Study in the "New Sociology of Education". In J. Shepherd, P. Virden, T. Wishart and Vulliamy, G. Eds. Whose Music: A Sociology of Musical Language. London: Latimer New Dimensions.

Willis, P. 2006. Foot Soldiers of Modernity: The Dialectics of Cultural

Consumption and the Twenty-First-Century School. In H. Lauder et. al. Eds.

Education, Globalization, and Social Change. Oxford: Oxford University Press: 507-523.

WNYC. 2014. The World's Most-Used Musical Sequence! WNYC, 6 July. http://www.wnyc.org/story/worlds-most-used-musical-sequence/.

Accessed: 14 June 2014. 